\title{
In Recognition of the 75th Birthday of Cornelius O. Horgan
}

Published online: 11 April 2019

(C) Springer Nature B.V. 2019

Cornelius ("Niall") Horgan celebrates his 75th birthday on May 16, 2019. In recognition of the impact of his work in the field of continuum mechanics and applied mathematics and to acknowledge his contributions to the Journal of Elasticity (both as author and member of the editorial board), this issue of the journal is being dedicated to him.

Niall Horgan is the Wills Johnson Professor of Applied Mathematics and Mechanics Emeritus in the School of Engineering and Applied Science, University of Virginia, Charlottesville, VA. He was educated at the National University of Ireland (B.Sc. 1964, M.Sc. 1965, Mathematical Sciences) and at the California Institute of Technology (Ph.D. 1970, Applied Mechanics). He held faculty positions at the University of Michigan, the University of East Anglia, the University of Houston and Michigan State University before joining the University of Virginia in 1988. He has held visiting summer appointments at Caltech (1979, 1981) and Cornell University (1982), and visiting professorships at Northwestern University (1977-1978), Caltech (1984-1985), Universita di Pisa (1996, 1997), Universita di Ferrara (2001, 2003), Universita di Lecce (2001, 2003), Universidad Politecnica de Catalunya (1999, 2003) and Dublin City University (2007, 2009-2010). His research interests are in continuum mechanics (mechanics of solids and materials) and applied mathematics, in which fields he has authored or co-authored fourteen invited book chapters, over 190 publications in refereed archival journals and numerous Conference Proceedings papers. The diversity of the research topics that he has investigated can be gleaned from the publication list to follow. Dr. Horgan is a lifetime member and Fellow of the American Society of Mechanical Engineers (ASME), a lifetime member of the Society of Engineering Science, a Fellow of the American Academy of Mechanics and a member of the International Society for the Interaction of Mechanics and Mathematics (ISIMM). He is a Charter Member of the Engineering Mechanics Institute, American Society of Civil Engineers (ASCE). He was one of the founding editors of Mathematics and Mechanics of Solids in 1995 and continues to serve on the Editorial Board of that journal as well as that of the J. of Elasticity and the new journal Mechanics of Soft Materials. He served on the editorial boards of the ASME Journal of Applied Mechanics, Applied Mechanics Reviews, SIAM J. on Applied Mathematics, International J. of Nonlinear Mechanics, and Annali dell'Universita di Ferrara, Sezione VII-Scienze Matematiche. He was awarded the degree of Doctor of Science (D.Sc.) by the 
National University of Ireland in 1983. He served on the Board of Directors, Society of Engineering Science from 1993-1999 and on the Executive Committee of ISIMM from 2002-2007. He was awarded the Eringen medal by the Society of Engineering Science in 2005 in recognition of sustained outstanding achievements in Engineering Science. He was awarded a Science Foundation Ireland E. T. S. Walton Fellowship at Dublin City University, Ireland in 2009-2010. He continues to actively contribute to research in elasticity and applied mathematics.

Jeremiah G. Murphy

Dublin City University, Dublin, Ireland

Giuseppe Saccomandi Università di Perugia, Perugia, Italy

This is a regular issue of the Journal of Elasticity and the articles appearing herein have not been solicited to honor this occasion. In 2004, the Journal of Elasticity dedicated Volume 74, No. 1 to Professor Horgan in recognition of his 60th birthday and to acknowledge his contributions to the Journal and to the field of mechanics. We are pleased to take the occasion of his 75 th birthday to once again recognize the contributions of Cornelius O. Horgan by dedicating this issue to him.

Roger Fosdick Editor-in-Chief University of Minnesota, Minneapolis, USA

Publisher's Note Springer Nature remains neutral with regard to jurisdictional claims in published maps and institutional affiliations. 